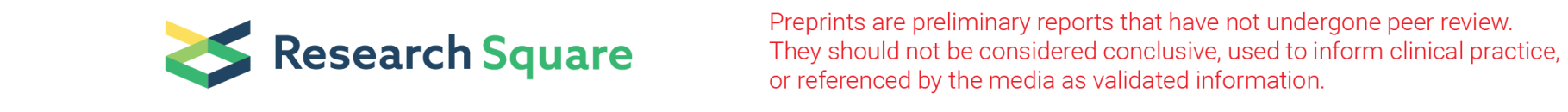

\title{
In Silico and In Vitro Investigations On Mutated IFNß-scFv Against Human Collagen Type II
}

\author{
Fatemeh Alimohammadi \\ University of Isfahan \\ Zohreh Hojati ( $\nabla$ z.hojati@sci.ui.ac.ir) \\ University of Isfahan https://orcid.org/0000-0003-4831-0123 \\ Mazdak Ganjalikhani-Hakemi \\ Isfahan University of Medical Sciences
}

\section{Research Article}

Keywords: Rheumatoid arthritis, mutated IFN $\beta-s c F v$, IFN $\beta 27+101$, scFv

Posted Date: November 9th, 2021

DOl: https://doi.org/10.21203/rs.3.rs-987486/v1

License: (1) This work is licensed under a Creative Commons Attribution 4.0 International License. Read Full License 


\section{Abstract}

Current medications for rheumatoid arthritis (RA), a common synovial autoimmune disease, are associated with adverse effects. Interestingly, interferon beta (IFN $\beta$ ), effective in multiple sclerosis (MS) treatment, also can help decreasing articular destruction in RA. Here, a novel fusion protein was introduced containing human mutated IFN $\beta$ (with mutations in 27th and 101th residues; IFN $\beta_{27+101}$ ) fused to a single chain fragment variable (scFv) antibody against human collagen type II for decreasing IFN $\beta_{27+101}$ off-targets (according to drug targeting benefits) in future in vivo and clinical experiments. After designing, bioinformatic analyses and the recombinant vector transfection into HEK293 cells, the mutated IFN $\beta$-scFv protein confirmation and function were assessed by SDS-PAGE, western blotting, ELISA, and real-time PCR. The fusion protein secondary and tertiary structures had proper folding. Also, the recombinant mRNA secondary structure considered stable. 2.35 fold difference between the test and negative control groups confirmed the scFv attachment to human collagen type II $(p=0.046) . M x A 25.68$ fold overexpression in peripheral blood mononuclear cells (PBMCs) treated with the recombinant protein compared with the non-treated sample $(p=0.0001)$, demonstrated IFN $\beta_{27+101}$ bioactivity as the fusion protein. In vitro and in silico studies verified function of mutated IFN $\beta$-scFv, however in vivo studies are proposed for further validation.

\section{Introduction}

Autoimmune diseases with a prevalence of more than $3 \%$ in the world are caused by the immune system aberration leading to inflammatory responses (Chen et al. 2019; Lee et al. 2020). Among them, rheumatoid arthritis (RA) is an autoimmune disorder of synovials that is defined by synovium inflammation which leads to articular destruction (Gibofsky 2014). In such diseases, the imbalance in the immune system results in losing the tolerance to the self-antigens and all purposes of the treatment are to rebalance it (Chen et al. 2019). In this regard, interferon beta (IFN $\beta$ ), a cytokine with the fibroblast cellular origin belonging to type I class of interferons, has anti-inflammatory and immunomodulatory properties making it a suitable candidate for treatment of autoimmune diseases (Meyer 2009; Rommer et al. 2019). This cytokine, considered as an effective drug for multiple sclerosis (MS) treatment, has also successful outcomes in animal models suffering RA (Triantaphyllopoulos et al. 1999; Tak et al. 1999; Jiang et al. 2020). Although the exact role of IFN $\beta$ in the treatment of RA is unknown, many studies have revealed several possible mechanisms including proinflammatory cytokines reduction, immunomodulatory cytokines elevation, regulatory T-cells induction, matrix metalloproteinases (MMPs) suppression, and preventing T-helper 17 differentiation (van Holten et al. 2002; Baecher-Allan et al. 2006; Ramgolam et al. 2009). Therefore, IFN $\beta$ has been effective in RA treatment in the reduction of synovial inflammation and cartilage destruction (van Holten et al. 2004; Smeets et al. 2000). Notably, Kay et al. (2016) have designed a mutated IFN $\beta$ in which Arg 27 and Val 101 residues have been substituted with Thr and Phe, respectively (Kay et al. 2016). The Thr substitution in the 27th residue makes one extra site of glycosylation and increases its stability, half-life, solubility, and biological activity compared with the wild type IFN $\beta$ with one site of N-glycosylation (Shin et al. 2012; Runkel et al. 1998; Karpusas et al. 1998). 
Also, it is noteworthy that the Phe 101 replacement in IFN $\beta$ has been enhanced the bioactivity of this protein, as indicated by a previous research (Goelz et al. 2000). Kay and her colleagues has reported that the presence of these two mutations in the IFN $\beta\left(\right.$ IFN $\left.\beta_{27+101}\right)$ caused 2.26 and 4.5 fold overexpression in mRNA and protein levels, respectively, and also improved bioactivity in comparison to the wild type one (Kay et al. 2016). Generally, single chain fragment variable (scFv) engineering technology has been maintained the antigen binding site (paratope), in spite of decreasing the size of antibody (Ahmad et al. 2012). Using these advantages, scFv has been applied in therapeutic applications and drug targeting (Daly et al. 2001; Harmsen et al. 2007). Precise drug delivery, as a novel therapeutic approach, has been reduced off-target, side effects, drug dosage, treatment costs and ultimately increased treatment effectiveness (Kehoe et al. 2013; Morrison et al. 2012). In this regard, Morrison et al. (2012) have investigated that a wild type IFNa, fused to multiple antibodies, has 100-time higher efficiency with lower side effects compared with a non-fused one (Morrison et al. 2012). In the present study, a fusion recombinant protein in which the human mutated IFN $\beta$ is fused to a ScFv antibody against human collagen type II (particularly located in joints) was introduced, for the first time. With the aim of reducing off-target of mutated IFN $\beta$ and reaching other above-mentioned advantages, it may be able to reach synovials in RA disorder, precisely.

Here, in silico and in vitro analyses were used to determine the function of the relative mRNA and protein. Using the in silico approach, recombinant mRNA secondary structure stability, recombinant protein secondary and tertiary structures, residues torsional angles, energy minimization of the predicted protein model and solubility of the fusion protein were accomplished. Subsequently, assessment of the recombinant gene construct expression in both RNA and protein levels and in vitro bioactivity of the purified recombinant fusion protein were done.

\section{Materials And Methods}

\section{Recombinant plasmid design}

Briefly, having obtained, the sequences of mutated IFN $\beta_{27+101}$ (Kay et al. 2016) and scFv (Kehoe et al. 2013) components $\left(V_{L}\right.$ and $\left.V_{H}\right)$ were embedded in the $C$-terminal and $\mathrm{N}$-terminal of the construct structure, respectively. Next, (Gly $\mathrm{Ser}_{3}$ sequence (Chen et al. 2013) was used as a scFv linker (connecting $V_{L}$ to $V_{H}$ ) and AEAAAKEAAAKAGS sequence (Grewal et al. 2015, 2017) was applied as an IFN $\beta$ linker through which the mutated IFN $\beta$ ( $\mathrm{mIFN} \beta$ ) attached to scFv. Also, human IFN $\beta$ signal peptide sequence obtained from the UniProt database (https://www.uniprot.org/uniprot/P01574) (Consortium 2019) was placed at the beginning of the construct, in order to recombinant protein secretion. Afterward, the amino acid sequence was converted to the nucleic acid sequence by the online server EMBOSS Backtranseq (https://www.ebi.ac.uk/Tools/st/emboss_backtranseq). For cloning into pcDNA3.1(+)_myc-His A vector, HindIII and EcoRI restriction sites were respectively considered at $5^{\prime}$ and $3^{\prime}$ of the recombinant construct (GenBank accession number: MN733992). Also, Myc and His6-tag sequences located in downstream of the construct were considered (Figs. 1a and 1b). 


\section{Secondary RNA structure}

In silico analysis of the recombinant mRNA was accomplished by Mfold online server (http://unafold.rna.albany.edu/?q

$$
=
$$

mfold) in order to assess the Gibbs free energy for the recombinant mRNA secondary structure.

\section{Protein molecular weight estimation}

The molecular weights including non-glycosylated and glycosylated proteins were calculated. In this regard, Protein Molecular Weight web server (https://www.bioinformatics.org/sms/prot_mw.html) (Stothard 2000) was used for calculating the non-glycosylated protein molecular weight. The N-linked glycosylated and O-linked glycosylated protein molecular weights were calculated by GlycoEP server (http://crdd.osdd.net/raghava/glycoep/submit.html) (Chauhan et al. 2013).

\section{Protein structure}

The fusion protein's secondary structure was determined by GOR-IV web server (https://npsaprabi.ibcp.fr/NPSA/npsa_gor4.html) (Deléage 2017). Using homology modeling, the tertiary structure was predicted by I-TASSER server (https://zhanglab.ccmb.med.umich.edu/I-TASSER/) (Yang et al. 2015; Roy et al. 2010; Zhang 2008). In addition, Ramachandran plot was drawn for the mutated IFNß-scFv fusion protein by RAMPAGE server (http://mordred.bioc.cam.ac.uk/ rapper/rampage.php). Also, Swiss PDB Viewer version 4.1 software (http://www.expasy.org/spdbv/) (Guex et al. 1997) was applied for energy minimization of the predicted model. The solubility of the protein was evaluated by PROSO II server (http://mbiljj45.bio.med.uni-muenchen.de:8888/prosoll/prosoll.seam) (Smialowski 2012).

\section{Recombinant plasmid construction}

The recombinant vector and the vector without insert (mock) were prepared by Macrogen (Korea). The recombinant vector was drawn by Snapgene software (Fig. 1c). The recombinant gene construct was sequenced. Then, the nucleotide BLAST (https://blast.ncbi.nlm.nih.gov/Blast.cgi) was applied for approving the sequencing results. After transformation of the recombinant and mock vectors into the competent E.coli TOP10, the plasmid extraction was accomplished by Miniprep plasmid extraction kit (Genet Bio, Korea). The recombinant vector was double digested with Hindlll and EcoRI restriction enzymes (Thermo Fisher Scientific, USA) and analyzed on 1\% TAE (Tris-Acetate-EDTA) agarose gel electrophoresis. 


\section{Cell culture and transfection}

Human embryonic kidney (HEK293) cell line was purchased from the Pasteur Institute, Iran. Cells were cultured in a Dulbecco-modified Eagle medium (DMEM, High Glucose, GlutaMAX ${ }^{\mathrm{TM}}$ ) with $10 \%$ fetal bovine serum (FBS) (Biowest, France) and 1\% penicillin/streptomycin (Sigma, Germany) at $37^{\circ} \mathrm{C}, 95 \%$ humidity and $5 \% \mathrm{CO} 2$ condition. 24h before transfection, HEK293 cells were seeded in 35mm tissue culture plates up to about $60 \%$ confluency. The fresh medium was refilled, 3 h prior to transfection. Then, the calcium phosphate protocol was used for transient transfection of $4 \mu \mathrm{g}$ recombinant (treated) and mock vectors in each plate (Chen 2011). Meanwhile, untransfected cells considered as a negative control. After $24 \mathrm{~h}$ incubation of transfected and untransfected cells at $37^{\circ} \mathrm{C}, 95 \%$ humidity and $5 \% \mathrm{CO} 2$, the fresh media were added and the cells were incubated for an extra $24 \mathrm{~h}$ at the same conditions.

\section{Protein purification}

The cell media was poured into Ni-NTA Sepharose column. After washing with the wash buffer $(20 \mathrm{mM}$ imidazole, $300 \mathrm{mM} \mathrm{NaCl}$ and $50 \mathrm{mM} \mathrm{NaH2PO4;} \mathrm{pH} 7.8$ ), the His6-tagged recombinant protein was detached by elution buffer ( $250 \mathrm{mM}$ imidazole, $300 \mathrm{mM} \mathrm{NaCl}, 50 \mathrm{mM} \mathrm{NaH} 2 \mathrm{PO} 4$; pH 7.8) (Emamzadeh et al. 2006). Then, the Bradford assay was carried out for determining the recombinant protein concentration (Bradford 1976).

\section{SDS-PAGE and western blotting}

The $12.5 \%$ sodium dodecyl sulfate-polyacrylamide gel electrophoresis (SDS-PAGE) was used and subsequently, the gel was stained by Coomassie brilliant blue method. Western blotting technique was carried out by the monoclonal anti-polyhistidine-peroxidase antibody (Sigma, Germany). To visualize the recombinant protein, the transferred polyvinylidene difluoride (PVDF) membrane was incubated for $2 \mathrm{~min}$ in the mixture solution of clarity ${ }^{\text {TM }}$ western enhanced chemiluminescence (ECL) substrate (Bio-Rad, USA) that was prepared according to manufacturer's instruction. Next, the PVDF membrane was exposed to the $\mathrm{X}$-ray film in darkness for $1 \mathrm{~min}$ and then, it was developed and fixed by the relative solutions for 1 and $5 \mathrm{~min}$, respectively.

\section{Binding measurement of ScFv in the fusion protein to human collagen type II by enzyme-linked immunosorbent assay (ELISA)}

An in-house ELISA was designed and performed for confirmation of the scFv attachment to human collagen type II. To do so, the human collagen type II (EMD Millipore, USA) was coated in the test and positive control wells of a 96-well microplate (Nunc, Denmark). After blocking and washing steps, the 
recombinant protein and the mouse anti-type II collagen IgG2b monoclonal antibody-biotinylated (Chondrex, USA) were added to the test and negative control wells, and the positive control wells, respectively, followed by incubation and washing. Then, the monoclonal anti-polyhistidine-peroxidase antibody (Sigma, Germany) was added to the test and negative control wells, and the horseradish peroxidase (HRP) streptavidin (BioLegend, USA) was added to the positive control wells. After incubating and washing, 3,3',5,5'-tetramethylbenzidine (TMB) substrate mixture solution (BioLegend, USA) that was prepared following the manufacturer's protocol, was added to the wells. Finally, stop solution was used and the optical density (OD) was determined by ELISA reader at $450 \mathrm{~nm}$.

\section{In vitro activity determination of mutated IFN $\beta$ in the fusion protein}

The biological activity of IFN $\beta_{27+101}$ was confirmed by $M x A$ induction measurement (Matas et al. 2016) in human peripheral blood mononuclear cells (PBMCs) treated with the recombinant protein. With this aim, human PBMCs were isolated from whole blood of a healthy donor using lymphoprep ${ }^{\mathrm{TM}}$ (Stemcell Technologies, Canada) gradient according to manufacturer protocol. 200000 cells/well were cultured in a 12-well plate by Roswell park memorial institute (RPMI) medium (Gibco, UK) supplemented with 10\% FBS at $37^{\circ} \mathrm{C}, 95 \%$ humidity and $5 \% \mathrm{CO} 2$ condition. According to the literature, the cells were treated for $24 \mathrm{~h}$ with $100 \mathrm{IU} / \mathrm{ml}(3 \mathrm{ng} / \mathrm{ml})$ of Rebif®(IFNß-1a) (Merck, Germany) and $3 \mathrm{ng} / \mathrm{ml}$ of the recombinant protein as a positive control and test, respectively (Dupont et al. 2002). Also, non-treated cells were stored for $24 \mathrm{~h}$ in the same condition as a negative control.

\section{RNA extraction and cDNA synthesis}

RNA extraction was carried out in two separate times, 48h after transfection of HEK293 cells and 24h after PBMCs treatment. Total RNA was isolated by RNeasy Mini Kit (Qiagen, Germany) following the protocol suggested by the manufacturer. Then, the RNA quantity and quality were determined by nanodrop apparatus. Next, cDNA synthesis was performed by RevertAid First Strand cDNA Synthesis Kit (Thermo Fisher Scientific, USA). Both the RNA and cDNA samples were kept at $-70^{\circ} \mathrm{C}$.

\section{Real-time PCR}

Real-time polymerase chain reaction (PCR) was performed using Applied Biosystems ${ }^{\circledR}$ real-time PCR device and Takara kit (SYBR ${ }^{\circledR}$ Premix Ex Taq ${ }^{\mathrm{TM}}$ II, Tli RNaseH Plus). As a housekeeping gene, EEF1A1 was used (Dehghanian et al. 2014) and specific primers for IFN $\beta$ and $M x A$ were designed by AllelelD7.0 and Oligo7 softwares (Table1). Real-time PCR reactions were prepared in a $20 \mu \mathrm{l}$ total volume with $0.5 \mathrm{pmol} / \mu \mathrm{l}$ from each primer of IFN $\beta$ and $E E F 1 A 1,0.25 \mathrm{pmol} / \mu \mathrm{l}$ from each primer of $M x A, 10 \mu \mathrm{l}$ SYBR $B$ Premix Ex Taq ${ }^{\mathrm{TM}} \mathrm{II}, 100 \mathrm{ng} / \mu \mathrm{l}$ cDNA, and $0.4 \mu \mathrm{l}$ of ROX Reference Dye. Real-time PCR program was carried out by primary denaturation for $2 \mathrm{~min}$ at $95^{\circ} \mathrm{C}$ and 40 cycles containing 10 s denaturation step at $95^{\circ} \mathrm{C}$, 
30s annealing step for IFN $\beta$ and $M x A$ at $58^{\circ} \mathrm{C}$ and $60^{\circ} \mathrm{C}$, respectively, 30 s extension step at $72^{\circ} \mathrm{C}$, and a final extension step for $3 \mathrm{~min}$ at $72^{\circ} \mathrm{C}$. The relative gene expression of IFN $\beta$ and $M x A$ were calculated by the $2^{-\Delta \Delta C t}$ method using the average cycle threshold $(C t)$ values of three independent experiments.

Table 1

Oligonucleotide primer sequences used for real-time PCR

\begin{tabular}{|ll|}
\hline Primer & Sequence \\
\hline IFN $\beta$ F & 5' GCTACAACTTGCTTGGATTC 3' \\
\hline IFN $\beta$ R & 5' ATAGATGGTCAATGCGGC 3' \\
\hline MxA F & 5' GCATTCCCAGACGGCATA 3' \\
\hline MXA R & 5' CAGAGGAGTAGGATTATCACACC 3' \\
\hline EEF1A1 F & 5' CCCTTCTGGCTTACACACT 3' \\
\hline EEF1A1 R & 5' TGAACCAAGGCATGTTAGCAC 3' \\
\hline
\end{tabular}

\section{Statistical analysis}

Statistical analysis was carried out using SPSS16.0 software (SPSS Inc, USA) through One-way ANOVA and Wilcoxon tests. Results were shown as mean percentage \pm relative standard deviation (SD). The $p<0.05$ was considered as meaningful.

\section{Results}

\section{Recombinant mRNA secondary structure}

Among 22 predicted structures, Gibbs free energy for the best one was defined as $\Delta G=-450.50 \mathrm{kcal} / \mathrm{mol}$. At the $5^{\prime}$ end of the recombinant mRNA, the first nucleotides did not have a stable hairpin as shown in Fig. 2a.

\section{Recombinant protein molecular weight}

The recombinant protein molecular weight (with the Myc and His6-tag) regardless of glycosylation was calculated 48.48kDa. Also, 2 and 12 positions were predicted for $\mathrm{N}$-linked glycosylation and O-linked glycosylation, respectively.

\section{Recombinant protein structure}

The recombinant protein secondary structure possessed 421 total residues (without considering signal peptide in the mature protein) consisting of 192 random coils (45.61\%), 120 helixes (28.50\%) and 109 strands (25.89\%) (Fig. 2b). The predicted tertiary structure of the recombinant protein with two recognized 
domains including the scFv domain and the mutated IFN $\beta$ (which are connected through a peptide linker) were illustrated in Fig. 3a. Next, the torsional angels outputs showed that $81.1 \%, 13.4 \%$ and $5.5 \%$ residues were placed in the favored, allowed and outlier regions, respectively (Fig. 3b). Energy minimization of the predicted model was estimated as $-20230.768 \mathrm{kcal} / \mathrm{mol}$ implying the mutated IFN $\beta-\mathrm{ScF}$ v fusion protein possessed an acceptable stability. Also, the solubility score of 0.777 with $71 \%$ accuracy showed that the fusion protein was classified as soluble.

\section{Recombinant plasmid confirmation}

The sequencing results of the recombinant construct was obtained (Fig. 4). In addition, the nucleotide BLAST approved the sequencing results (Fig. 5a). The double digestion with two restriction enzymes including HindIII and EcoRI clearly showed two bands of 1326bp and 5458bp represented the insert (recombinant construct) and the vector backbone, respectively (Fig. 5b).

\section{Verification of the recombinant protein expression by SDS-PAGE and western blot assay}

A single $70 \mathrm{kDa}$ band was detected on SDS-PAGE. Next, western blotting analysis confirmed the identity of the fusion protein and demonstrated the purified protein was suitable for the following analysis (Figs. 6a, $6 b, S 1$ and S2).

\section{Confirmation of scFv attachment to human collagen type II by ELISA}

According to One-way ANOVA analysis, the optical density of the test and negative control groups were $0.73 \pm 0.10(p=0.046)$ and $0.31 \pm 0.07$, respectively. The 2.35 fold significant difference between the test and negative control samples indicated the attachment of the scFv domain of the recombinant protein to human collagen type II. Also, the optical density of the positive control group was $2.18 \pm 0.39(p=0.000)$, which showed 2.98 fold elevation in comparison to the test sample $(p=0.000)$ (Fig.7). Results were reported as a mean \pm SD of three identical repeats of each experiment.

\section{Overexpression of $m I F N \beta_{27+101}$ in treated HEK293 cells}

Based on One-way ANOVA analysis, IFN $\beta$ expression level in untransfected cells was measured as $1.02 \pm$ 0.28 , which was considered as a negative control in HEK293 cells. The expression of IFN $\beta$ in samples transfected with the recombinant (treated) and mock vectors was determined as $10.04 \pm 2.48(p=0.008)$ and $1.02 \pm 0.25$, respectively. Like untransfected cells, a basic expression of IFN $\beta$ was observed in the cells containing the mock vector. The 9.84 fold significant overexpression was obtained in the treated cells in comparison to the negative control and mock samples. However, there was no meaningful difference between the two latest groups (Fig. 8a).

\section{Induced $M x A$ expression by the mutated IFN $\beta-s c F v$}

The biological activity of the mutated IFN $\beta$-scFv protein was validated by induced $M x A$ expression in PBMCs treated with the fusion protein at in vitro condition. According to Wilcoxon analysis, $M x A$ 
expression in the test, positive and negative control samples were measured as $25.94 \pm 1.85(p=0.0001)$, $27.87 \pm 0.32(p=0.0001)$, and $1.01 \pm 0.08(p=1.0)$, respectively. The 25.68 fold significant difference between the test and negative control samples represented the high activity level of the mutated IFN $\beta$ scFv. Treated samples with either the mutated IFN $\beta-s c F v$, or Rebif ${ }^{\circledR}$ showed a strong meaningful difference of $M x A$ expression compared with the non-treated sample. However, there was no significant difference between the mutated IFN $\beta$-scFv and Rebif ${ }^{\circledR}$. Therefore, the biological activity of the mutated IFN $\beta$-scFv was approximately similar to the Rebif ${ }^{\circledR}$, as a commercial medicine of IFNß-1a (Fig. 8b).

\section{Discussion}

The RA disorder classified as an autoimmune disease characterizing by synovial destruction (Firestein 2003). Due to the features of IFN $\beta$ immunomodulation and anti-inflammation, this cytokine considered as a reliable treatment for MS (Meyer 2009). The RA and MS diseases possess the similar immunopathogenesis. Researches have shown the successful outcome of IFN $\beta$ in RA treatment of animal models and it may be effective in human RA therapy (Triantaphyllopoulos et al. 1999; Tak et al. 1999). On the other hand, current medications for RA including immunosuppressant agents and tumor necrosis factor (TNF) inhibitors have many adverse effects like increased risk of malignancies (Leandro et al. 2001; Bojinca et al. 2012). Thus, lack of more effective and safe medications for RA treatment is considerable.

From the view points of literatures, Grewal et al. (2015) have reported that the targeted mutant IFNa has better performance than targeted wild type IFNa (Grewal et al. 2015). Also, Grewal and his colleagues (2017) have constructed a wild type IFN $\beta$ fused to an antibody for effectively targeting activated T-cells surface antigen in autoimmune disease treatment (Grewal et al. 2017). Based on these studies, the targeted mutant IFNa and the targeted IFN $\beta$ have shown suitable performances of the transcripts including the higher stabilities and also the higher translation yields of the proteins with lower off-targets (Grewal et al. 2015). In this regard, for the first time, a recombinant protein containing the human mutant IFN $\beta_{27+101}$ (with the higher level of expression and activity) fused to the scFv against human collagen type II was defined. This fusion protein may be applicable in future in vivo and clinical experiments with the prospect of conducting the mutated IFN $\beta$ precisely to the synovials for RA treatment.

With this aim, mRNA secondary structure of the construct was evaluated by Gibbs free energy. Using this analysis, the stability of the mRNA secondary structure was validated. Accordingly, such long mRNA, containing fused parts with different ribonucleotide compositions, could be stable before the translation with the in silico look-out. Furthermore, the first ribonucleotide compositions, at the $5^{\prime}$ end of the recombinant mRNA, did not form a stable hairpin structure. Such secondary structures can occasionally hinder the ribosomes to translate proteins. Albeit, the ribonucleotide compositions surrounded these structures can also be effective on the stability of these hairpins, the base paring probabilities in these structures can prevent ribosomes from reaching the start codon. Notably, the in silico molecular weight estimation showed that the fusion protein's molecular weight without glycosylation was $48.48 \mathrm{kDa}$. Also, the analysis showed that two predicted sites for N-linked glycosylation which were located in the 
IFN $\beta_{27+101}$ part, added $8 \mathrm{kDa}$ (Shin et al. 2012) and raised the molecular weight up to 56.5kDa. Moreover, according to O-linked glycosylation molecular weight of $1 \mathrm{kDa}$ (Daskalova et al. 2010), 12 predicted relative sites raised the total molecular weight up to $70 \mathrm{kDa}$, approximately. Notably, the fusion protein had suitable folding at predicted secondary and tertiary structures. The assessed torsional angles also showed that about $93 \%$ of the residues were in the favored and allowed region and it could demonstrate the perfect folding to reach a suitable biological activity. In addition, the analysis of homology modeling of this fusion protein showed that it had acceptable stability with considered energy minimization at pre/post-translational processes. The computational analysis of the fusion protein illustrated that this protein with different domains classified as soluble. This feature can facilitate the achievement of the fusion protein to the target at in vitro and also future in vivo and clinical assays with lower off-target to reduce its side effects.

Following the computational analyses, in vitro assays were considered. Accordingly, having designed and synthesized, the recombinant vector was confirmed by sequencing and double digestion with HindIII/EcoRI restriction enzymes. Then, it was transfected into HEK293 cells to get human posttranslational modifications such as common glycosylations. Using SDS-PAGE, a single 70kDa band, approximately the same as in silico estimated molecular weight, was observed. This protein band was recognized as the considered recombinant protein by western blotting method. Next of the protein detection, the ELISA test indicated that the 2.35 fold difference between the test and negative control samples confirmed the efficient reactivity of the ScFv with human collagen type II. Also, it demonstrated that fusing the IFN $\beta_{27+101}$ to the scFv did not prevent scFv binding to the antigen. In addition, 2.98 fold difference was observed between the test and positive control samples. In fact, the scFv has one capacity to bind the target compared with the whole antibody with two capacities. Due to the avidity effect, the overall forces of the whole antibody-antigen interaction are greater than scFv-antigen interaction. It is noteworthy that the avidity is not equal to the sum up of two affinities and addition of each extra affinity increases the avidity, exponentially (Müller-Loennies et al. 2000; Batra et al. 2002). Therefore, the binding avidity difference between the fusion protein and the positive control was acceptable. Regarding to the gene expression analysis, transfection of the cells with the recombinant plasmid was led to 9.84 fold overexpression of IFN $\beta$. Biological activity of IFN $\beta_{27+101}$, the other component of this fusion protein, could be successfully assessed by the IFN $\beta$-stimulated gene evaluation of $M x A$. MxA is one of the significant IFN-stimulated genes of superfamily of IFN-induced GTPase, which also comprises immunityrelated GTPases (IRGs) and guanylate-binding proteins (GBPs). Furthermore, the Jak-STAT signaling pathway and IFN-a induction are controlled by $M x A$ during virus infection. $M x A$ plays an immunosuppressive role in TAK1-IKKa/ $\beta$-NF-KB signaling pathway activation and following proinflammatory cytokines production in human macrophages (Zhou et al. 2020). Thus, this gene has the highest specificity and has proven to be a biomarker of IFN $\beta$ bioactivity (Matas et al. 2016; Gilli et al. 2006). Based on the biological activity analysis, 25.68 fold elevation in $M x A$ expression in PBMCs treated with the recombinant protein in comparison with the non-treated samples confirmed the intact bioactivity of the fused mutant IFN $\beta_{27+101}$. Also, the data represented that the biological activity of IFN $\beta_{27+101}$ in this fusion protein was almost the same as Rebif® (a prescribed medicine for MS treatment). In conclusion, 
the function of the mutated IFN $\beta$-scFv protein was confirmed by in silico and in vitro analyses. However, in vivo studies are proposed for the future validation of these findings.

\section{Declarations}

Acknowledgments The authors thank for The Graduate Office of University of Isfahan for kindly financial support (Grant number: 9033).

\section{Data availability statement}

All the data are presented in the manuscript and supplementary files and all data are available on request. Also, all files meet the submission requirements on the journal's homepage.

\section{Compliance with Ethical Standards}

Conflict of interests The authors declare that there are no competing interests associated with the manuscript.

Ethical Approval All procedures performed in studies involving human participants were in accordance with the ethical standards of the university of Isfahan and/or national research committee and with the 1964 Helsinki declaration and its later amendments or comparable ethical standards. Also, informed consents were received from all healthy donors of whole blood.

\section{References}

1. Chen Y, Sun J, Liu H, Yin G, Xie Q (2019) Immunotherapy deriving from CAR-T cell treatment in autoimmune diseases. J Immunol Res. https://doi.org/10.1155/2019/5727516

2. Lee $\mathrm{KH}$, Ahn BS, Cha D, Jang WW, Choi E, Park S et al (2020) Understanding the immunopathogenesis of autoimmune diseases by animal studies using gene modulation: A comprehensive review. Autoimmun Rev 19:102469. https://doi.org/10.1016/j.autrev.2020.102469

3. Gibofsky A (2014) Epidemiology, pathophysiology, and diagnosis of rheumatoid arthritis: A Synopsis. Am J Manag Care 20(7 Suppl):S128-S135

4. Meyer O (2009) Interferons and autoimmune disorders. Joint Bone Spine 76:464-473. https://doi.org/10.1016/j.jbspin

5. Rommer PS, Milo R, Han M, Satyanarayan S, Sellner J, Hauer L et al (2019) Immunological aspects of modern MS therapeutics. Front Immunol 10:1564. https://doi.org/10.3389/fimmu.2019.01564

6. Triantaphyllopoulos KA, Williams RO, Tailor H, Chernajovsky Y (1999) Amelioration of collageninduced arthritis and suppression of interferon- $y$, interleukin-12, and tumor necrosis factor a production by interferon- $\beta$ gene therapy. Arthritis. Rheum 42: 90-99. https://doi.org/10.1002/15290131(199901)42:1<90::AID-ANR12>3.0.CO;2-A 
7. Tak P, Hart Bt, Kraan M, Jonker M, Smeets T, Breedveld F (1999) The effects of interferon beta treatment on arthritis. Rheumatology 38:362-369. https://doi.org/10.1093/rheumatology/38.4.362

8. Jiang J, Zhao M, Chang C, Wu H, Lu Q (2020) Type I interferons in the pathogenesis and treatment of autoimmune diseases. Clin Rev Allerg Immu 59:248-272. https://doi.org/10.1007/s12016-02008798-2

9. van Holten J, Plater-Zyberk C, Tak PP (2002) Interferon- $\beta$ for treatment of rheumatoid arthritis? Arthritis Res 4:346-352. https://doi.org/10.1186/ar598

10. Baecher-Allan C, Hafler DA (2006) Human regulatory T cells and their role in autoimmune disease. Immunol Rev 212:203-216. https://doi.org/10.1111/j.0105-2896.2006.00417.x

11. Ramgolam VS, Sha Y, Jin J, Zhang X, Markovic-Plese S (2009) IFN- $\beta$ inhibits human Th17 cell differentiation. J Immunol 183:5418-5427. https://doi.org/10.4049/jimmunol.0803227

12. van Holten J, Reedquist K, Sattonet-Roche P, Smeets TJ, Plater-Zyberk C, Vervoordeldonk MJ, Tak P (2004) Treatment with recombinant interferon- $\beta$ reduces inflammation and slows cartilage destruction in the collagen-induced arthritis model of rheumatoid arthritis. Arthritis Res Ther 6:R239R249. https://doi.org/10.1186/ar1165

13. Smeets TJ, Dayer JM, Kraan MC, Versendaal J, Chicheportiche R, Breedveld FC, Tak P (2000) The effects of interferon- $\beta$ treatment on synovial inflammation and expression of metalloproteinases in patients with rheumatoid arthritis. Arthritis Rheum 43: 270-274. https://doi.org/10.1002/15290131(200002)43:2<270::AID-ANR5>3.0.C0;2-H

14. Kay M, Hasan-Abad AM, Hojati Z, Korbekandi H (2016) Targeted mutations in Val101 and Arg27 interferon beta protein increaseits transcriptional and translational activities. Cytokine 78:1-6. https://doi.org/10.1016/j.cyto.2015.11.019

15. Shin YK, So MK,. Lee JM, Yang JH, Yoo JU, Byun TH, Kim JT, Oh HK, Yoon HC, Ahn JS, Song K, Jin JH (2012) Human interferon-beta mutein. United States Patent US 8101716:B2

16. Runkel L, Meier W, Pepinsky RB, Karpusas M, Whitty A, Kimball K, Brickelmaier M, Muldowney C, Jones W, Goelz SE (1998) Structural and functional differences between glycosylated and nonglycosylated forms of human interferon- $\beta$ (IFN- $\beta$ ). Pharm Res 15:641-649. https://doi.org/10.1023/a:1011974512425

17. Karpusas M, Whitty A, Runkel L, Hochman P (1998) The structure of human interferon- $\beta$ : implications for activity. Cell Mol Life Sci 54:1203-1216

18. Goelz SE, Cate RL, Chow EP, Pepinsky RB (2000) Muteins of IFN- $\beta$. United States Patent US 6127332

19. Ahmad ZA, Yeap SK, Ali AM, Ho WY, Alitheen NBM, Hamid M (2012) scFv antibody: principles and clinical application. Clin Dev Immunol 2012:980250. https://doi.org/10.1155/2012/980250

20. Daly SJ, Dillon PP, Brennan J, Dunne L, Fitzpatrick J, O'Kennedy R (2001) Production and analytical applications of scFv antibody fragments. Anal Lett 34:1799-1827. https://doi.org/10.1081/AL100106113

21. Harmsen M, De Haard H (2007) Properties, production, and applications of camelid single-domain antibody fragments. Appl Microbiol Biotechnol 77:13-22. https://doi.org/10.1007/s00253-007-1142- 
22. Kehoe J, Gardiner JL, Ort T, Picha K, Ryan M, Wheeler J (2013) Antibodies binding human collagen II. United States Patent US 8394378:B2

23. Morrison SL, Huang TH, Xuan C (2012) Interferon-antibody fusion proteins demonstrating potent apoptotic and anti-tumor activities. United States Patent US 8258263:B2

24. Chen X, Zaro JL, Shen WC (2013) Fusion protein linkers: property, design and functionality. Adv Drug Deliv Rev 65:1357-1369. https://doi.org/10.1016/j.addr.2012.09.039

25. Grewal I, Khare S, Gresser M, Syed R (2015) Engineered antibody-interferon mutant fusion molecules. United States Patent US 20150139951:A1

26. Grewal I, Khare S, Gresser M (2017) Engineered antibody-interferon fusion molecules for treatment of autoimmune diseases. United States Patent US 9783589:B2

27. Consortium U (2019) UniProt: a worldwide hub of protein knowledge. Nucleic Acids Res 47:D506D515. https://doi.org/10.1093/nar/gky1049

28. Stothard $P$ (2000) The sequence manipulation suite: JavaScript programs for analyzing and formatting protein and DNA sequences. Biotechniques 28:1102-1104. https://doi.org/10.2144/00286ir01

29. Chauhan JS, Rao A, Raghava GP (2013) In silico platform for prediction of N-, O-and C-glycosites in eukaryotic protein sequences. PLoS One 8:e67008. https://doi.org/10.1371/journal.pone.0067008

30. Deléage G (2017) ALIGNSEC: viewing protein secondary structure predictions within large multiple sequence alignments. Bioinformatics 33:3991-3992. https://doi.org/10.1093/bioinformatics/btx521

31. Yang J, Yan R, Roy A, Xu D, Poisson J, Zhang Y (2015) The I-TASSER Suite: Protein structure and function prediction. Nat Methods 12:7-8. https://doi.org/10.1038/nmeth.3213

32. Roy A, Kucukural A, Zhang Y (2010) I-TASSER: a unified platform for automated protein structure and function prediction. Nat Protoc 5:725-738. https://doi.org/10.1038/nprot.2010.5

33. Zhang Y (2008) I-TASSER server for protein 3D structure prediction. BMC Bioinformatics 9:40

34. Guex N, Peitsch MC (1997) SWISS-MODEL and the Swiss-Pdb Viewer: an environment for comparative protein modeling. electrophoresis 18: 2714-2723.

https://doi.org/10.1002/elps.1150181505

35. Smialowski P, Doose G, Torkler P, Kaufmann S, Frishman D (2012) PROSO II-a new method for protein solubility prediction. FEBS J 279:2192-2200. https://doi.org/10.1111/j.17424658.2012.08603.x

36. Chen Y (2011) Calcium phosphate transfection of eukaryotic cells. Bio-protocol 1: 86e. https://doi.org/ 10.21769/BioProtoc.86

37. Emamzadeh AR, Hosseinkhani S, Sadeghizadeh M, Nikkhah M, Chaichi MJ, Mortazavi M (2006) cDNA cloning, expression and homology modeling of a luciferase from the firefly Lampyroidea maculata. J Biochem Mol Biol 39:578-585. https://doi.org/10.5483/bmbrep.2006.39.5.578 
38. Bradford MM (1976) A rapid and sensitive method for the quantitation of microgram quantities of protein utilizing the principle of protein-dye binding. Anal Biochem 72:248254. https://doi.org/10.1016/0003-2697(76)90527-3

39. Matas E, Bau L, Martínez-Iniesta M, Romero-Pinel L, Mañé-Martínez MA, Cobo-Calvo Á, MartínezYélamos S (2016) MxA mRNA expression as a biomarker of interferon beta response in multiple sclerosis patients. J Neuroimmunol 291:73-77. https://doi.org/10.1016/j.jneuroim.2015.12.015

40. Dupont SA, Goelz S, Goyal J, Green M (2002) Mechanisms for regulation of cellular responsiveness to human IFN- $\beta$ 1a. J Interferon Cytokine Res 22:491-501. https://doi.org/10.1089/10799900252952280

41. Dehghanian F, Hojati Z (2014) Comparative insight into expression of recombinant human VEGF111b, a newly identified anti-angiogenic isoform, in eukaryotic cell lines. Gene 553:57-62. https://doi.org/10.1016/j.gene.2014.10.002

42. Firestein GS (2003) Evolving concepts of rheumatoid arthritis. Nature 423:356-361. https://doi.org/10.1038/nature01661

43. Leandro MJ, Isenberg DA (2001) Rheumatic diseases and malignancy? is there an association? Scand J Rheumatol 30:185-188. https://doi.org/10.1080/030097401316909486

44. Bojinca V, Janta I (2012) Rheumatic diseases and malignancies, 7. Maedica, pp 364-371

45. Daskalova SM, Radder JE, Cichacz ZA, Olsen SH, Tsaprailis G, Mason H, Lopez LC (2010) Engineering of $N$. benthamiana $L$. plants for production of $\mathrm{N}$-acetylgalactosamine-glycosylated proteins-towards development of a plant-based platform for production of protein therapeutics with mucin type 0-glycosylation. BMC Biotechnol 10:62. https://doi.org/10.1186/1472-6750-10-62

46. Müller-Loennies S, MacKenzie CR, Patenaude SI, Evans SV, Kosma P, Brade H, Brade L, Narang S (2000) Characterization of high affinity monoclonal antibodies specific for chlamydial lipopolysaccharide. Glycobiology 10:121-130. https://doi.org/10.1093/glycob/10.2.121

47. Batra SK, Jain M, Wittel UA, Chauhan SC, Colcher D (2002) Pharmacokinetics and biodistribution of genetically engineered antibodies. Curr Opin Biotechnol 13:603-608. https://doi.org/10.1016/S09581669(02)00352-X

48. Zhou X, Zhang L, Lie L, Zhang Z, Zhu B, Yang J et al (2020) MxA suppresses TAK1-IKKa/ $\beta-N F-K B$ mediated inflammatory cytokine production to facilitate Mycobacterium tuberculosis infection. $J$ Infection 81:231-241. https://doi.org/10.1016/j.jinf.2020.05.030

49. Gilli F, Marnetto F, Caldano M, Sala A, Malucchi S, Capobianco M, Bertolotto A (2006) Biological markers of interferon-beta therapy: comparison among interferon-stimulated genes MXA, TRAIL and XAF-1. Mult. Scler 12:47-57. https://doi.org/10.1191/135248506ms1245oa

\section{Figures}




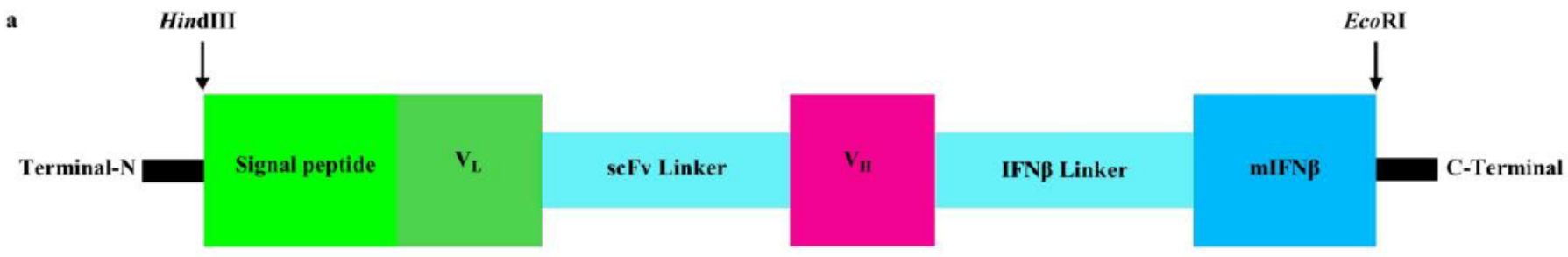

b
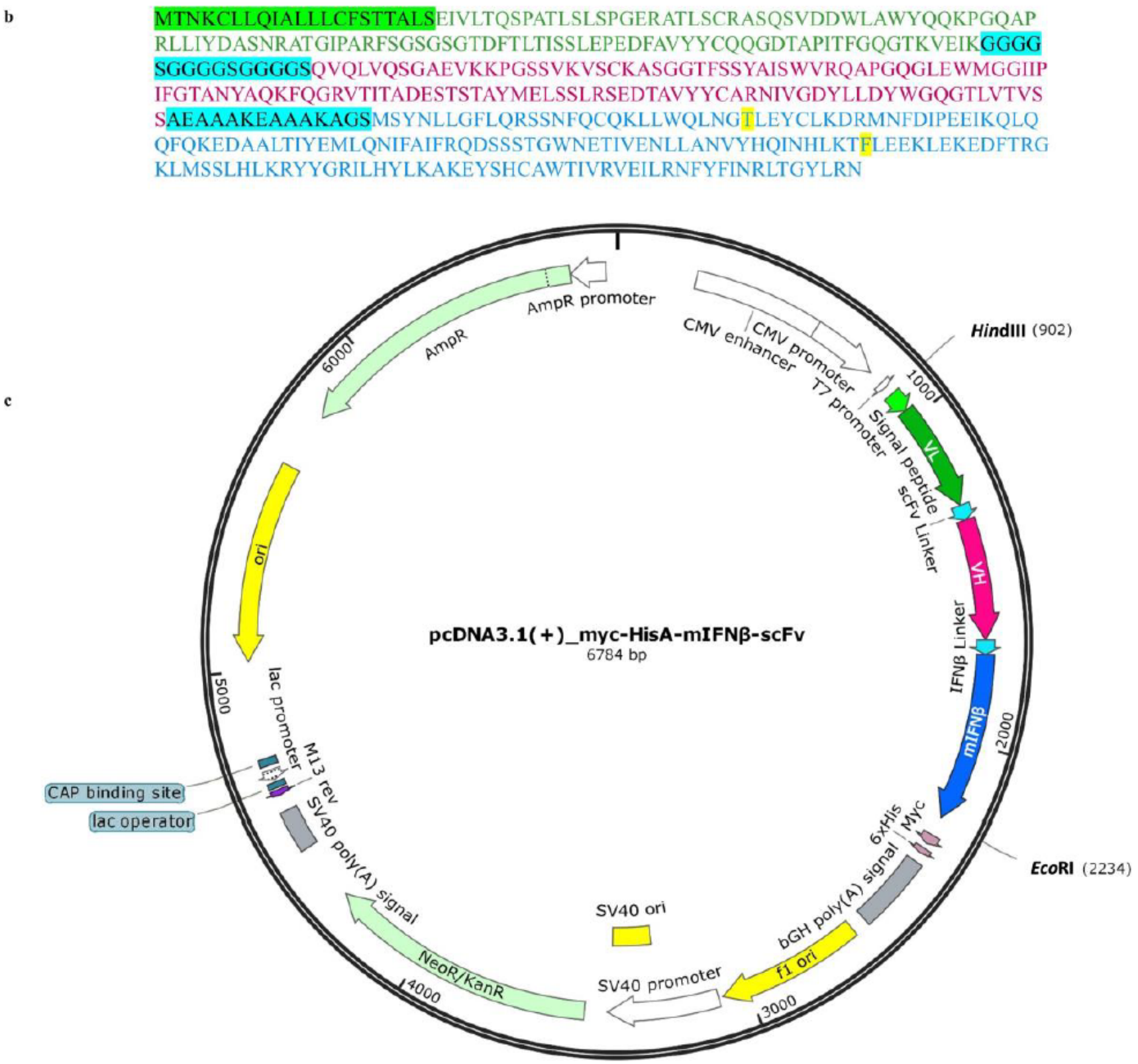

\section{Figure 1}

The mutated IFN $\beta$-scFv fusion molecule. (a) The schematic illustration of the recombinant construct. (b) The fusion protein's amino acid sequence. The yellow highlighted amino acids (27 and 101 residues of interferon beta) were substituted in the mutated IFN $\beta$. Colors in $a$ and $b$ are in conformity with each other. (c) The recombinant vector pcDNA3.1(+)_myc-HisA-mIFN $\beta$-scFv schematic representation drawn by Snapgene software 


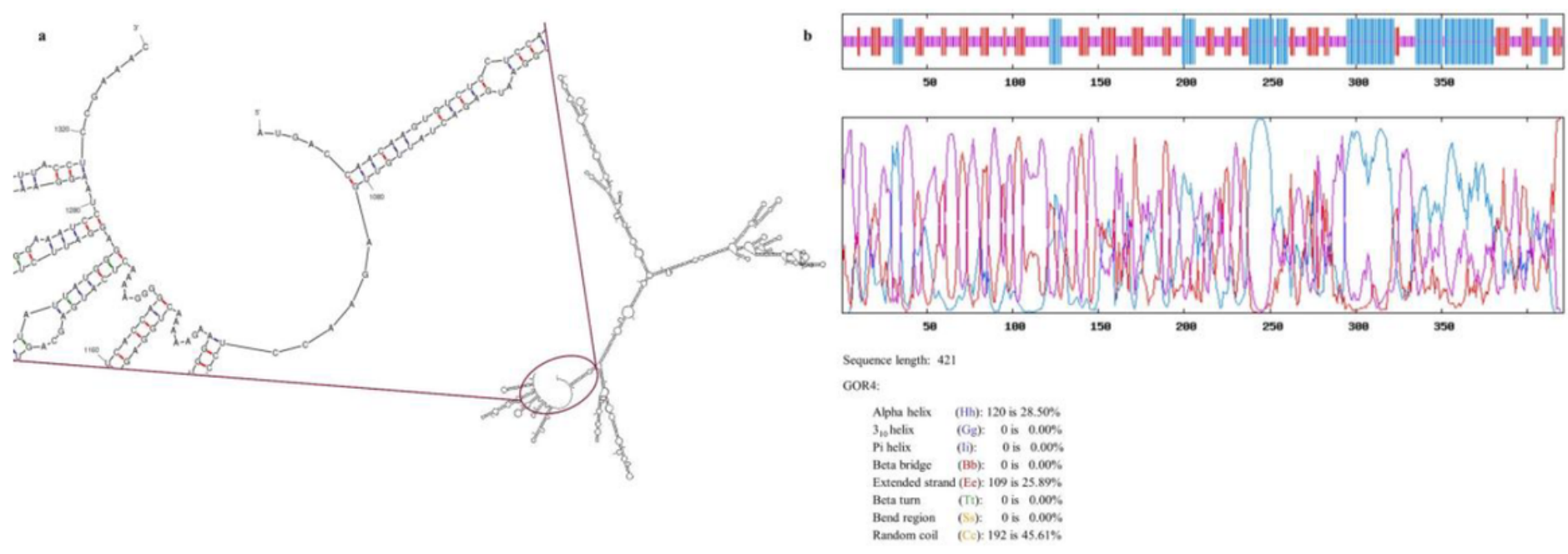

Figure 2

Recombinant mRNA and protein analysis. (a) Folding structure analysis of the mutated IFN $\beta$-scFv recombinant mRNA and start codon's position in this structure. (b) Secondary structure analysis of the mutated IFN $\beta$-scFv recombinant protein
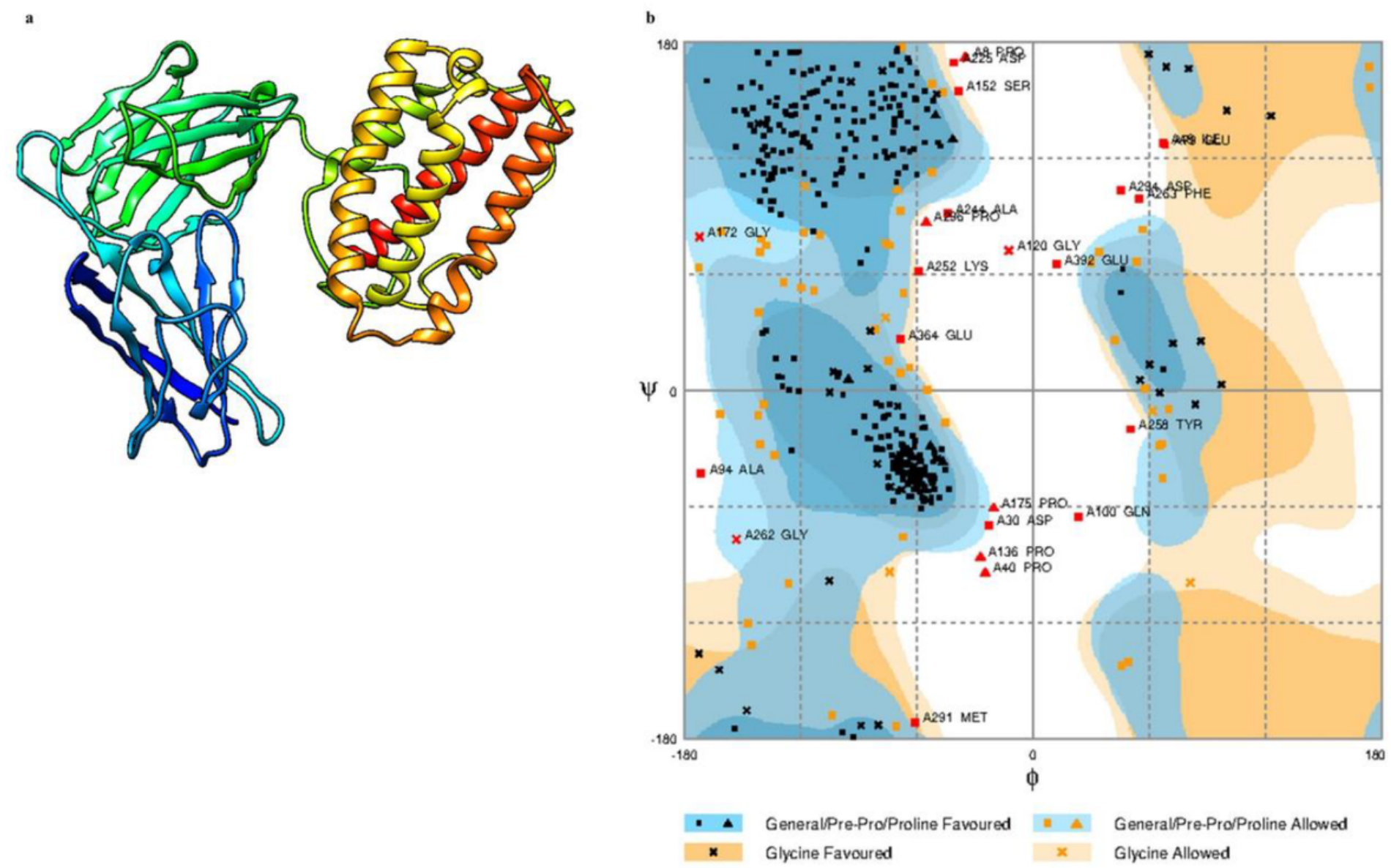

Figure 3 
Recombinant protein folding analysis. (a) Schematic molecular view of the recombinant protein depicted by I-TASSER web server. (b) The torsional angels of the predicted recombinant protein model by Ramachandran plot. Out of 421 total residues, 340 (81.1\%), 56 (13.4\%) and 23 (5.5\%) were placed in the favored (core Beta), allowed (core alpha), and outlier regions (core left-handed alpha)

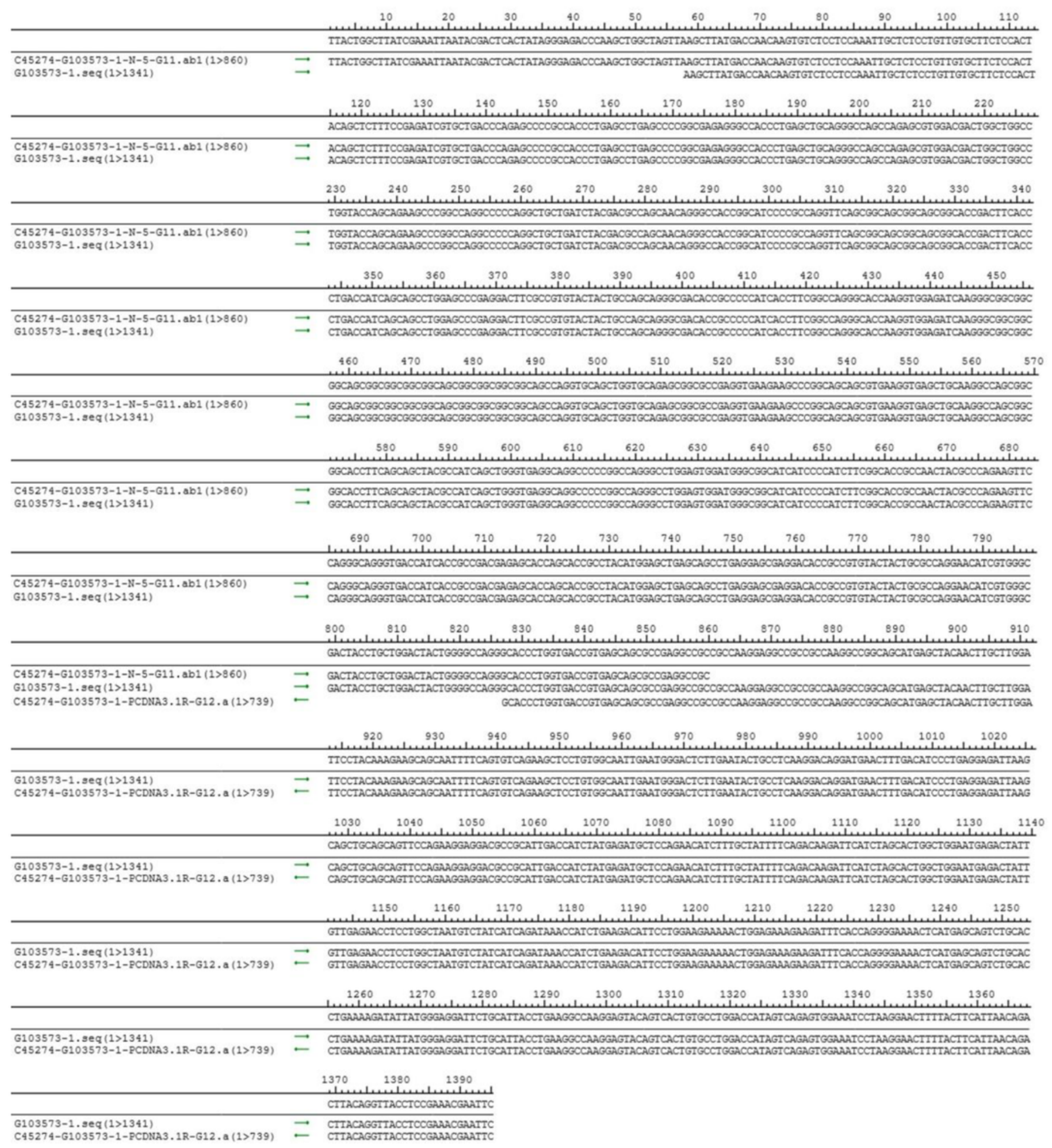

\section{Figure 4}



Alignment Scores
$<40$
$40-50$
$50-80$
$80-200$
$>=200$

Distribution of the top 1 Blast Hits on 1 subject sequences

\begin{tabular}{rrrrrr}
1 & 1 & Query & & 1 & 1 \\
1 & 250 & 500 & 750 & 1000 & 1250 \\
\hline
\end{tabular}

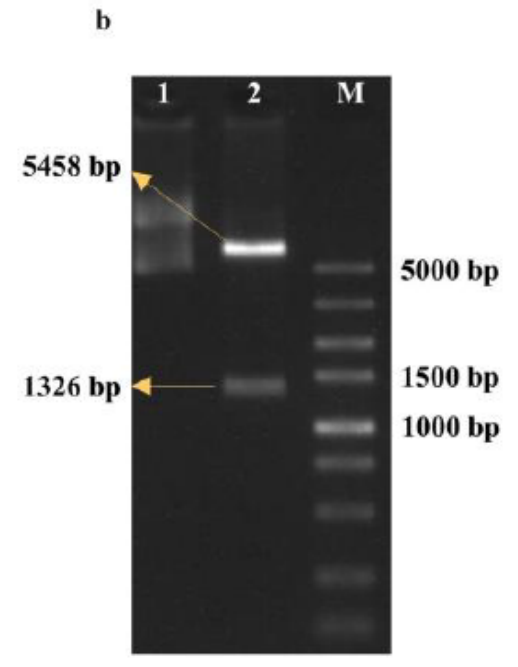

\section{Figure 5}

Recombinant plasmid confirmation. (a) Verifying the sequencing results by the nucleotide BLAST. (b) The double digestion of the recombinant vector; Lane 1: The non-digested recombinant vector, Lane 2: The digested recombinant vector with HindIII and EcoRI restriction enzymes, M: DL5000 DNA Marker, (Cat. Number: M0047) (LifeSct LLC, USA) 
a

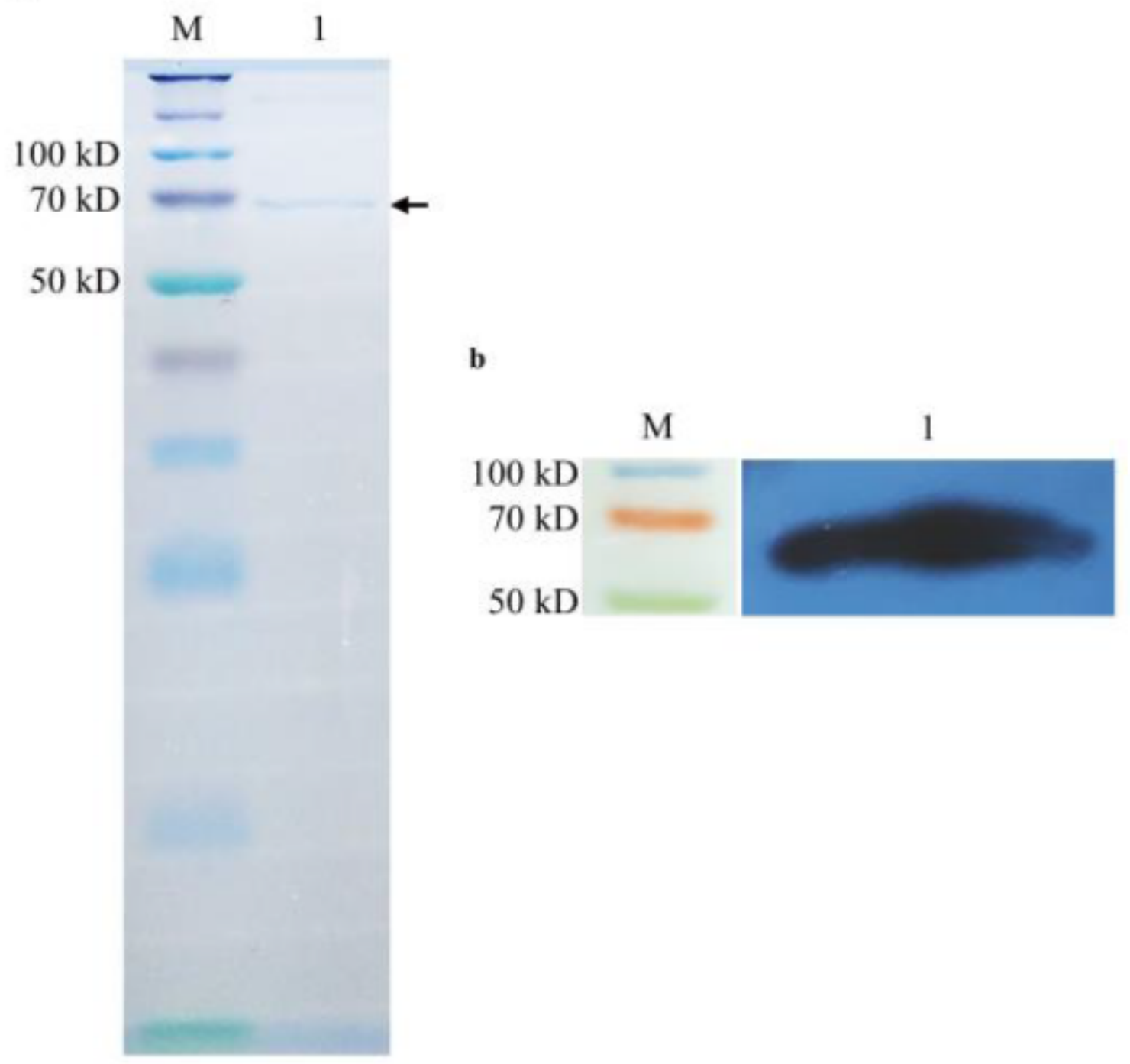

Figure 6

SDS-PAGE and western blotting. (a) Lane 1: Purified mutated IFN $\beta$-scFv protein on SDS-PAGE (the recombinant protein is defined by black arrow), Lane M: Protein marker, (Cat. Number: 26634) (Thermo Fisher Scientific, USA), (b) Lane 1: The spot of the mutated IFNß-scFv exposed on X-ray film, Lane M: Protein marker, (Cat. Number: 26634) (Thermo Fisher Scientific, USA) 


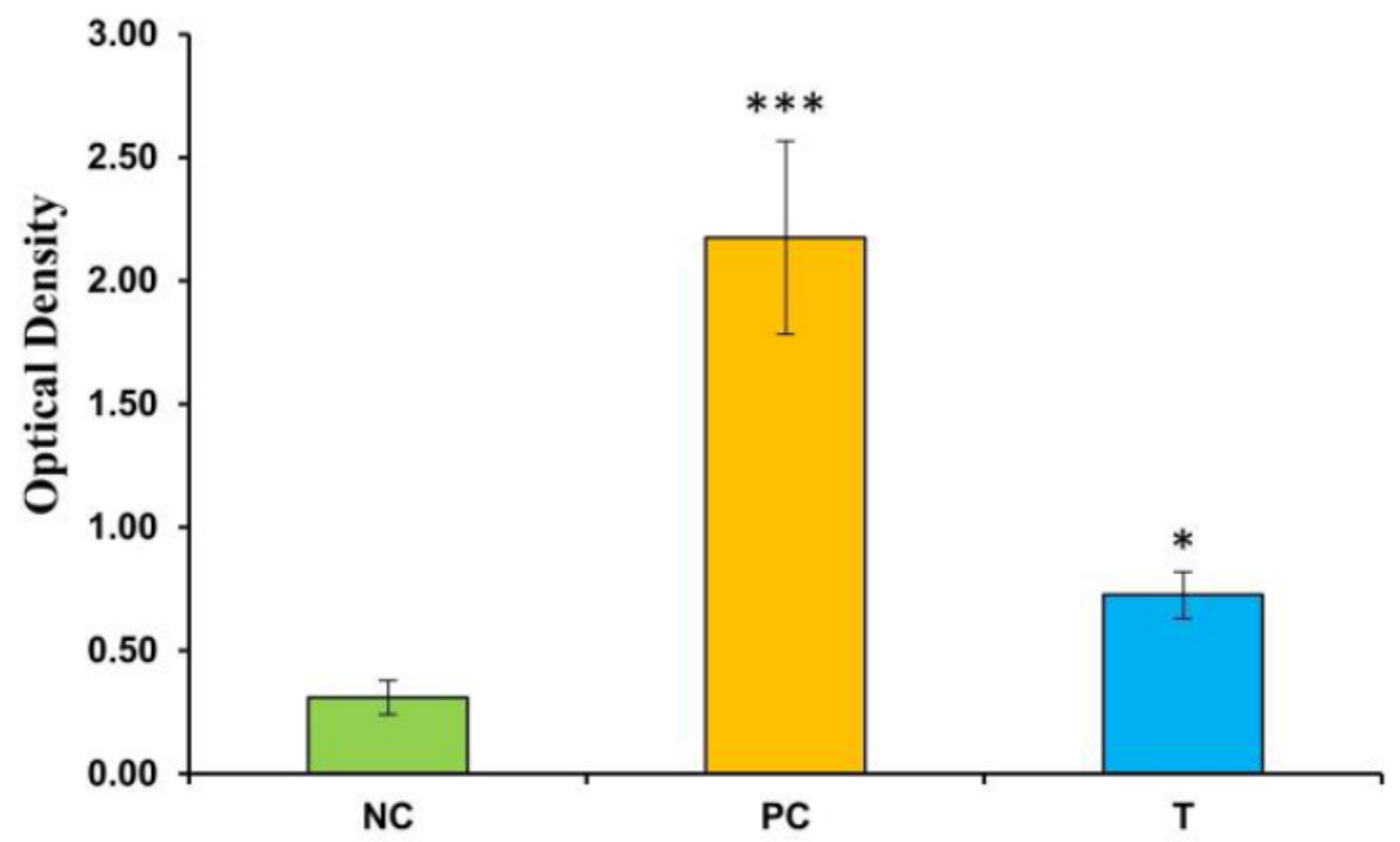

Figure 7

Verification of the mutated IFNß-ScFv attachment to human collagen type II by ELISA. The meaningful difference between the test and negative control samples $(p<0.05)$ confirmed the binding of scFv (in the mutated IFN $\beta$-scFv protein) to human collagen type II. NC, PC, and T represented the negative control, positive control and test, respectively. The asterisk (*) shows the statistical significance

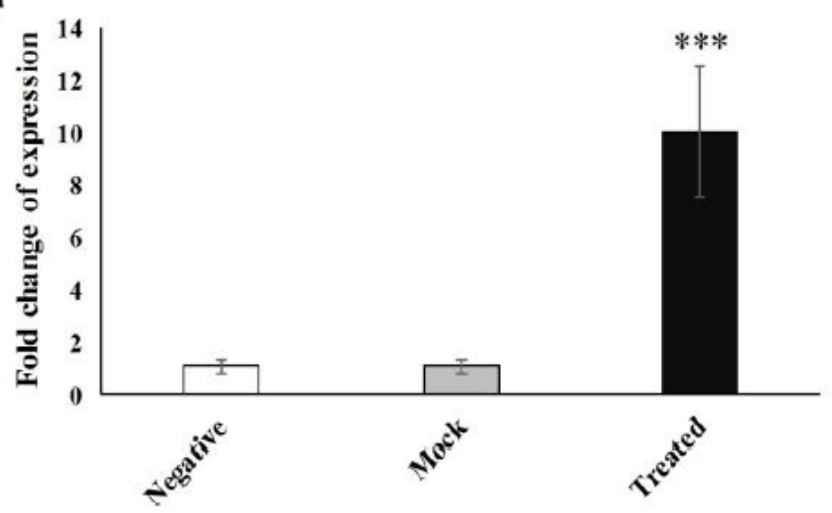

b

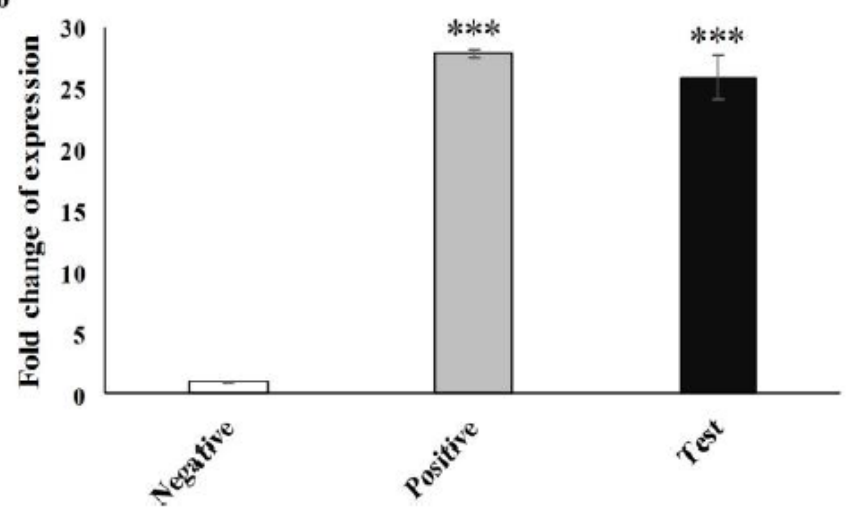

Figure 8 
Real-time PCR analysis. (a) Assessment of the expression of mutated IFN $\beta$-scFv gene construct. IFN $\beta$ expression in the treated sample had a significant difference compared with the negative control and mock samples $(p<0.05)$, and between the two latest groups, no meaningful difference was observed. (b) Validation of the mutated IFN $\beta 27+101$ biological activity by MxA expression assessment. The test and positive control samples had a strong significant difference in MxA expression with the negative control sample $(p<0.05)$ and none with each other, which confirmed the IFN $\beta 27+101$ bioactivity (in the mutated IFN $\beta$-scFv fusion protein). The asterisk $(*)$ expresses statistical significance

\section{Supplementary Files}

This is a list of supplementary files associated with this preprint. Click to download.

- S1.jpg

- S2.jpg 